\title{
Antibacterial Action and Physicochemical Properties of Stabilized Silver and Gold Nanostructures on the Surface of Disperse Silica
}

\author{
I. Mukha ${ }^{1}$, A. Eremenko', G. Korchak ${ }^{2}$, A. Michienkova ${ }^{2}$ \\ ${ }^{1}$ Chuiko Institute of Surface Chemistry of NAS of Ukraine, Kyiv, Ukraine \\ ${ }^{2}$ Marzeev Institute of Hygiene and Medical Ecology of AMS of Ukraine, Kyiv, Ukraine \\ E-mail:annaerem@ukr.net \\ Received November 10, 2009; revised December 4, 2009; accepted December 29, 2009
}

\begin{abstract}
This work is devoted to the synthesis and stabilization of nanosized $\mathrm{Ag} / \mathrm{SiO}_{2}$ and $\mathrm{Au} / \mathrm{SiO}_{2}$ disperse materials and investigation their morphology, optical and antimicrobial properties. First, $\mathrm{Ag}$ and $\mathrm{Au}$ nanoparticles (NPs) were produced in colloids via chemical $(\mathrm{Ag})$ or photochemical $(\mathrm{Au})$ reduction of appropriate ions. To prevent the oxidation of Ag NPs in colloid solution, external binary stabilizing agents PVP and SDS were used. Then, Ag and Au NPs (0.01-0.05\% wt) were adsorbed from their colloid solutions on high disperse silica surface $\left(\mathrm{S}_{\mathrm{sp}}=260 \mathrm{~m}^{2} / \mathrm{g}\right)$ and samples prepared were dried. Materials obtained were studied by UV-vis, XRD, and TEM methods. Ag and Au NPs adsorbed on silica demonstrated a fair crystallinity in XRD. The surface plasmon resonance (SPR) band positions inherent to Ag and Au NPs on silica surface as well as the intensities of optical spectra were stable during 7 month and more. Obtained $\mathrm{Ag}$ NPs in colloids and $\mathrm{Ag} / \mathrm{SiO}_{2}$ composites demonstrated excellent antimicrobial activity against a series of the microorganisms (Escherichia coli, Staphylococcus aurous, and Candida albicans). Au/ $\mathrm{SiO}_{2}$ samples did not reveal any bactericide properties relative to the test microorganisms grown. The mechanisms of $\mathrm{Ag}(\mathrm{Au}) \mathrm{NPs}$ interaction with silica surface were analyzed.
\end{abstract}

Keywords: Silver, Gold Nanoparticles, Binary Stabilizer PVP and SDS, Adsorption, High Disperse Silica, Antimicrobial Activity

\section{Introduction}

Water related infections belong to the one of the main health problems. The most dangerous water pathogenic pollutions such as Escherichia coli, Staphylococcus aurous are resistant to biodegradation. Silver nanoparticles (NPs) or silver ions have long been known to have strong inhibitory and bactericidal effect in solutions and composites with silica films and particles $\left(\mathrm{Ag} / \mathrm{SiO}_{2}\right)$ with developed surface area [1,2]. In case of $\mathrm{Ag} / \mathrm{SiO}_{2}$ application, the specific surface area of silica is of great importance for effective adsorption of the species desirable. That is why developed silica surface covered with $\mathrm{OH}$ groups offers unique environment for the fixation and stabilization of nanosized silver and gold particles $(\mathrm{Ag}$ and Au NPs) for applications in optics, sensing, catalysis and as bactericides. However, Ag NPs are unstable on silica surface under ambient conditions due to fast oxida- tion [3]. It is important to prevent or inhibit the aggregation of NPs and oxidation process at the nanocluster formation stage, especially in case of silver. There are some methods to prevent the contact of Ag NPs with environment such as the protection with the inverse micelles, polymers, or their introduction into the solid materials, metal oxides or polymer films. Thus, stabilizing agents used for NPs surface modification control the particles formation, growth and aggregation rate $[4,5]$.

Various methods are available for the NPs preparation. The most widely used techniques are photo- or radiation method in presence of stabilizers, and chemical reduction using sodium tetrahydroborate, hydrazine, glucose, sodium citrate, and other reactants [6-10].

Previously we synthesized stable Ag and Au NPs within silica films prepared using sol-gel method via thermal reduction of appropriate metal ions [11]. These films were bright colored, transparent, stable and had 
characteristic SPR bands belonging to Ag or $\mathrm{Au}$ NPs. However, Ag clusters formed on disperse silica surface were found to be stable only for a few days [3]. The self-agglomeration and oxidation of Ag NPs were detected also within the porous silica films [12]. Photochemically generated Ag and Au NPs prepared in colloid solutions aggregated during 4-5 weeks, and Ag NPs were covered with oxide layer $[9,10,13,14]$.

We suppose that the combination of the surfactant and polymer as the metal NPs stabilizers proposed for solution in $[15,16]$ can be successfully used to prevent the oxidation and aggregation of Ag NPs in adsorbed state on high disperse silica surface in air.

The aim of this work was the synthesis of stable nanosized $\mathrm{Ag} / \mathrm{SiO}_{2}$ and $\mathrm{Au} / \mathrm{SiO}_{2}$ disperse materials using binary stabilizer SDS/PVP and investigation of their morphology, optical and antimicrobial properties.

\section{Experimental Section}

\subsection{Initial Reagents}

$\mathrm{HAuCl}_{4}, \mathrm{AgNO}_{3}$ (Merck); Sodium dodecyl sulfate (SDS, Sigma Aldrich), Polyvinylpyrrolidone (PVP, grade: VFS 42-1491-85(Russia), FW=12000); Sodium tetrahydroborate $\left(\mathrm{NaBH}_{4}\right.$, Fluka), Benzophenone (BP, Aldrich), $i$-propanol Sigma Aldrich); high-dispersed silica (HDS, brand A-300 with $\mathrm{S}_{\mathrm{sp}}=260 \mathrm{~m}^{2} / \mathrm{g}$, "Khlorvinil").

\subsection{Ag and Au NPs Preparation}

$\mathrm{Ag} / \mathrm{SiO}_{2}$ and $\mathrm{Au} / \mathrm{SiO}_{2}$ powders were obtained by adsorption of previously synthesized Me NPs colloids (total metal concentration $1,5 \cdot 10^{-4} \mathrm{~mol} / \mathrm{l}$ ) on the surface of thermal treated HDS under stirring at room temperature. All Me colloids (0.01-0.05 wt \% Me) were absorbed on silica surface.

Nanosized Ag particles in colloid solution were prepared via chemical reduction of $\mathrm{AgNO}_{3}$ with $\mathrm{NaBH}_{4}$ analogously to [9] in presence of SDS/PVP mixture previously dissolved in water. The reaction scheme is:

$$
\begin{gathered}
4 \mathrm{Ag}^{+}+\mathrm{nBH}_{4}^{-}+3 \mathrm{nH}_{2} \mathrm{O} \rightarrow 4 \mathrm{Ag}+\mathrm{nH}_{2} \mathrm{BO}_{3}{ }^{-}+4 \mathrm{nH}^{+}+2 \mathrm{nH}_{2} \\
8 \mathrm{Ag}^{+}+\mathrm{nBH}_{4}^{-}+3 \mathrm{nH}_{2} \mathrm{O} \rightarrow 8 \mathrm{Ag}+\mathrm{nH}_{2} \mathrm{BO}_{3}^{-}+8 \mathrm{nH}^{+}
\end{gathered}
$$

Synthesized Ag NPs were adsorbed on the surface of $\mathrm{HDS}$ pretreated at $500 \mathrm{C}$. The $\mathrm{Ag} / \mathrm{SiO}_{2}$ powders were dried at $85-95^{\circ} \mathrm{C}$ during 4 hours.

$\mathrm{Au}$ colloids were synthesized via photochemical reduction of $\mathrm{HAuCl}_{4}$ [10] under $\mathrm{UV}$-irradiation in water- $i$ propanol solution with mercury lamp irradiation $(\lambda=254$ $\mathrm{nm}$ ) in presence of mesoporous $\mathrm{SiO}_{2}$ powder with adsorbed benzophenone as the photocatalyst of $\mathrm{Au}^{3+}$ ions reduction and SDS as a stabilizer. Total reaction scheme including formation of ketyl-radicals from benzophenone and $i$-propanol is:

$$
\begin{aligned}
& \mathrm{R}_{2} \mathrm{C}^{\cdot} \mathrm{O}^{-}+\mathrm{Au}^{3+} \rightarrow \mathrm{R}_{2} \mathrm{C}=\mathrm{O}+\mathrm{Au}^{2+} \quad\left(\mathrm{R}=\mathrm{CH}_{3}, \mathrm{C}_{6} \mathrm{H}_{5}\right) \\
& \qquad \mathrm{R}_{2} \mathrm{C}^{\cdot} \mathrm{OH}+\mathrm{Au}^{3+} \rightarrow \mathrm{R}_{2} \mathrm{C}=\mathrm{O}+\mathrm{Au}^{2+}+\mathrm{H}^{+} \\
& \text {disproportionation: } \quad 2 \mathrm{Au}^{2+} \rightarrow \mathrm{Au}^{3+}+\mathrm{Au}^{+} \\
& \text {reduction of } \mathrm{Au}(\mathrm{I}): \quad \mathrm{R}_{2} \mathrm{C}^{\cdot} \mathrm{O}^{-}+\mathrm{Au}^{+} \rightarrow \mathrm{R}_{2} \mathrm{C}=\mathrm{O}+\mathrm{Au}^{0}
\end{aligned}
$$

Synthesized $\mathrm{Au}$ NPs were adsorbed on the surface of $\mathrm{HDS}$ pretreated at $500^{\circ} \mathrm{C}$. The $\mathrm{Au} / \mathrm{SiO}_{2}$ powders were dried and treated at $500^{\circ} \mathrm{C}$ during 5 hours.

\subsection{Characterization}

UV-VIS Absorption Spectroscopy studies were per-formed with a Perkin-Elmer Lambda 35 spectrophotometer in the wavelength range of 200-1000 nm. Measurements were made in $1 \mathrm{~cm}$ quartz cuvettes. Diffuse reflection spectra of $\mathrm{Me} / \mathrm{SiO}_{2}$ powders were recorded with Perkin- Elmer Lambda 35 spectrophotometer with a Labsphere RSA-PR-20 integrating sphere and handled using a Kubelka-Munk equation. The crystal structures of powders were determined with X-ray diffractometer (DRON-4-07, $\mathrm{CuK}_{\alpha}$ ). The size and morphology of the $\mathrm{Ag}$ and $\mathrm{Au}$ nanoparticles in colloids and on silica surface were characterized with a JOEL JEM-100C transmission electron microscope (accelerating potential 100kV).

\subsection{Antimicrobial Properties Study}

Antimicrobial actions of NPs in colloids and on silica surface were determined using suspension tests according to the European standards EN 13727:2004 [17] and EN 13624:2002 [18]. Test microorganisms Staphylococcus aureus ATC C 6538, Escherichia coli K12 NCTC 10538 were used for evaluation of bactericidal activity and Candida albicans ATCC 10231 was used for evaluation of fungicidal activity of disinfectants.

Test microorganisms were grown in agar medium:

Tryptic soy agar for bacteria and Saburo agar for Candida albicans (HIMEDIA, India). Their specific quantities in test suspension (bacteria - up to $1.5 \cdot 10^{8}$ $5.0 \cdot 10^{8}$ colony-forming units $\mathrm{CFU} / \mathrm{ml}$ or $8 \mathrm{lg}$, yeast-like fungi - up to $1.5 \cdot 10^{7}-5.0 \cdot 10^{7} \mathrm{CFU} / \mathrm{ml}$ or $7 \mathrm{lg}$ ) were monitored with a KFK-3 photoelectric colorimeter $(\lambda=$ $620 \mathrm{~nm}$, cuvette length $-10 \mathrm{~mm}$ ).

Suspension method involved mixing of $1 \mathrm{ml}$ of the test microorganisms with $1 \mathrm{ml}$ of diluent and then adding 8 $\mathrm{ml}$ of the test disinfectant. The experimental mixture was maintained at $(20.0 \pm 1.0)^{\circ} \mathrm{C}$ for the chosen contact times of $1 ; 2 ; 4 ; 24 \mathrm{~h}$. After exposing for the required contact time, $1 \mathrm{ml}$ was transferred to $9 \mathrm{ml}$ of neutralizer $(8.0 \mathrm{ml}$ $0.1 \% \mathrm{Na}_{2} \mathrm{~S}+1.0 \mathrm{ml} \mathrm{H} \mathrm{H}_{2} \mathrm{O}$ ). After neutralizing for $5 \mathrm{~min} 1.0$ $\mathrm{ml}$ of the test mixture was taken in duplicate and plated to detect survived test microorganisms. After incubation the numbers of survived bacteria (at $37.0 \pm 1.0^{\circ} \mathrm{C}$ for 24 to 
$48 \mathrm{~h}$ ) or fungi (at $30.0 \pm 1.0^{\circ} \mathrm{C}$ for $48 \mathrm{~h}$ ) in each sample were found.

The reduction values $\mathrm{R}=\mathrm{N}_{0}-\mathrm{N}_{\mathrm{a}}$ were expressed in decimal logarithms: $\operatorname{lgR}=\lg \mathrm{N}_{0}-\lg \mathrm{N}_{\mathrm{a}}$, where $\mathrm{N}_{0}$ - number of cells per $\mathrm{ml}$ in the test mixtures at the beginning and $\mathrm{N}_{\mathrm{a}}-$ that at the end of the contact time $t$. An excellent antibacterial activity was in agreement with 99.9 percent reduction of microorganisms $(\mathrm{R}>99.9 \%)$. This related to $51 \mathrm{~g}$ for bacteria and $41 \mathrm{~g}$ for fungi.

\section{Results and Discussion}

SPR absorption band positions of the Ag and Au colloids obtained were at 417 and $530 \mathrm{~nm}$ respectively, and the average particle diameters were of 10-12 $\mathrm{nm}$ for $\mathrm{Ag}$ and 20-30 nm for Au (Figures 1(a), 1(b), 2(a), 2(b)).

When NPs from prepared colloids were adsorbed on the HDS surface adsorption equilibrium occurred in a few minutes. An irreversible binding of both types of NPs with silica was found. It should be noted, that a homogeneous distribution of the NPs was observed also after thermal treatment of bright-colored $\mathrm{Ag} / \mathrm{SiO}_{2}$ at $85-90^{\circ} \mathrm{C}$ and $\mathrm{Au} / \mathrm{SiO}_{2}$ at $500^{\circ} \mathrm{C}$.

In the X-ray spectra of $\mathrm{Me} / \mathrm{SiO}_{2}$ powders two clear reflections were noticed at $2 \theta=38^{\circ}$ and $44^{\circ}$, more evident in case of $\mathrm{Au} / \mathrm{SiO}_{2}$. These peaks were assigned to (111) and (200) planes of cubic Me respectively.

Sample color and characteristic optical spectra of $\mathrm{Me}$ NPs in colloids were stable for 7 month and more. $\mathrm{Ag} / \mathrm{SiO}_{2}$ powders treated at $85-90^{\circ} \mathrm{C}$ were stable and oxidation-resistant on the developed HDS surface. $\mathrm{Au} / \mathrm{SiO}_{2}$ powders were stable after treatment at $500^{\circ} \mathrm{C}$ after destruction of protective shell.

The oxidation of Ag NPs on silica run after the thermal treatment of $\mathrm{Ag} / \mathrm{SiO}_{2}$ powders in air at app. $200^{\circ} \mathrm{C}$ due to destruction of organic protective shell and further interaction of $\mathrm{Ag}$ NPs with oxygen: $4 \mathrm{Ag}+\mathrm{O}_{2} \leftrightarrow 2 \mathrm{Ag}_{2} \mathrm{O}$.

Repeated treatment of $\mathrm{Ag}_{2} \mathrm{O} / \mathrm{SiO}_{2}$ at $250-300^{\circ} \mathrm{C}$ resulted in the reduction of yellow color of Ag NPs which disappeared again when the samples were cooled to the room temperature. Obviously the presence of stabilizing shell was necessary to protect Ag NPs on HDS surface against oxidation.

Separately used PVP and SDS stabilizers provided the stability of $\mathrm{Ag}$ on the $\mathrm{SiO}_{2}$ during several days after drying. After that the oxidation of Ag on silica surface occurred and the color disappeared. The protection mechanism of Ag NPs in solution by binary PVP/SDS stabilizer consisted in capping of Ag NPs by SDS chains and absorption by PVP functional groups in accordance with [19]. Double shell of SDS micelles and polymer probably prevented Ag NPs against contact with oxygen. Binding of the metal nanoclusters by the surface of HDS is strong due to interaction between the functional groups of binary stabilizer of Ag NPs and OH-groups of silica surface [9] TEM image of $\mathrm{Ag} / \mathrm{SiO}_{2}$ is shown in the Figure 1(d). According to [20], PVP in specified concentration range was adsorbed irreversibly. At the same time the binary shell did not prevent biocide action of Ag NPs as it is shown later.
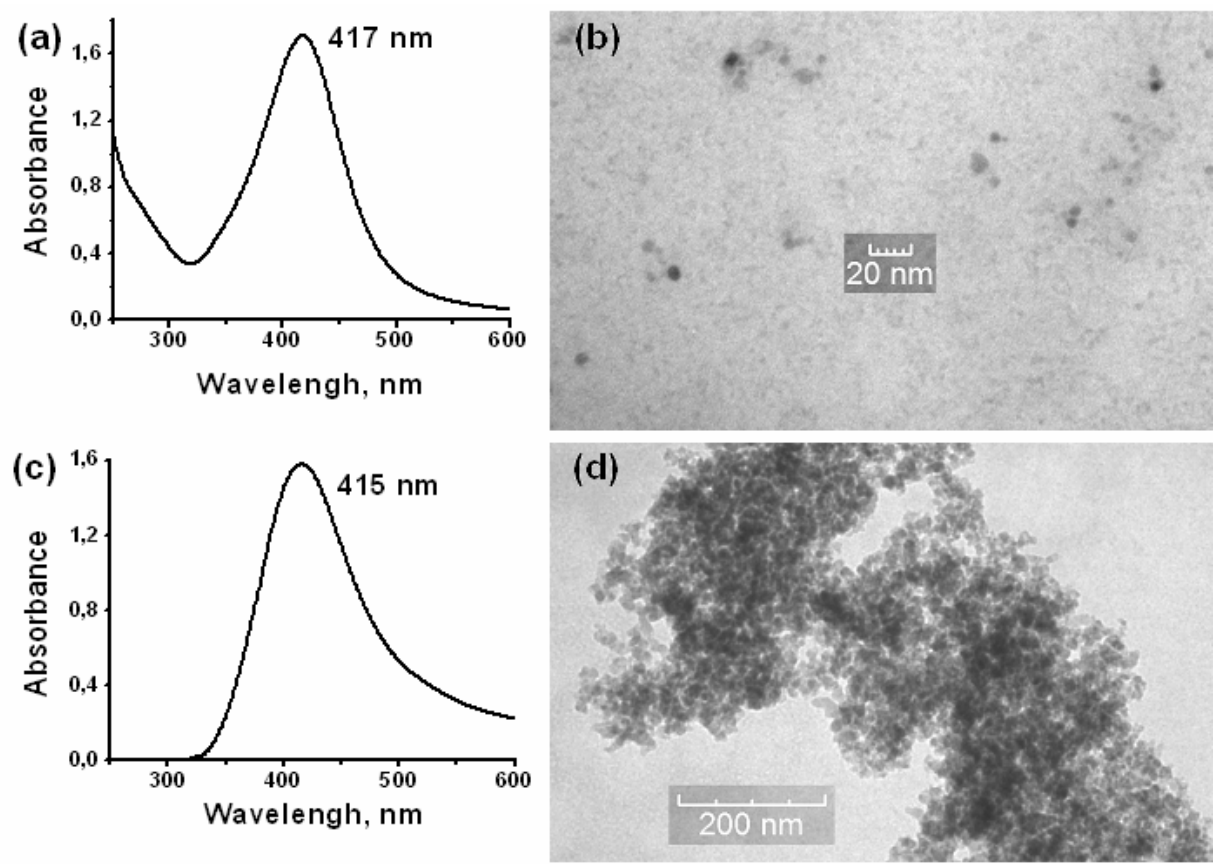

Figure 1. Optical spectra (a.c) and TEM images (b,d) of Ag NPs colloid and $\mathrm{Ag} / \mathrm{SiO}_{2}$ powder respectively. 

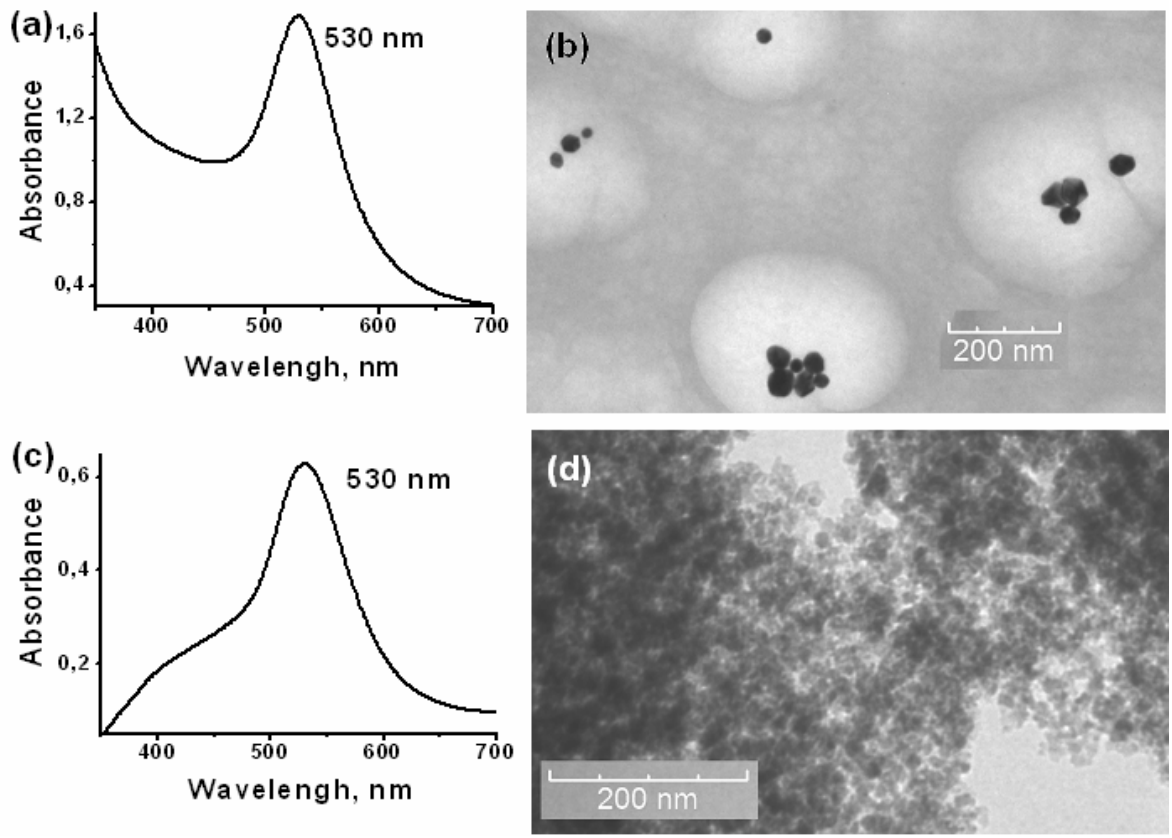

Figure 2. Optical spectra (a.c) and TEM images (b,d) of Au NPs colloid and $\mathrm{Au} / \mathrm{SiO}_{2}$ powder respectively.

In accordance with [21,22], colloid silica particles in presence of SDS micelles after drying formed 3D structures with developed porosity. We suggested that $\mathrm{Au}$ NPs produced within colloid using only SDS stabilizer were localized within these "secondary" pores of HDS. TEM image of $\mathrm{Au} / \mathrm{SiO}_{2}$ is shown in the Figure 2(d). Such location can provide an explanation for strong binding of Au NPs by silica after $500 \mathrm{C}$ treatment.

Absorption maxima in the DRS of $\mathrm{Ag} / \mathrm{SiO}_{2}$ and $\mathrm{Au} / \mathrm{SiO}_{2}$ powders calculated via Kubelka-Munk equation were equal to those in colloid solutions. This is an evidence of nanoscale dimensionality of metal particles after absorption (Figure 1(c), 2(c)).

\section{1. $\mathrm{Me} / \mathrm{SiO}_{2}$ Composites Antimicrobial Activity}

To explain the inhibitor effects of silver on bacteria it was suggested that silver reacted with proteins by combining the thiol (-SH) groups leading to the bacteria inactivation [23]. In this work we examined the antibacterial activity of $\mathrm{Ag} / \mathrm{SiO}_{2}$ and $\mathrm{Au} / \mathrm{SiO}_{2}$ suspensions and of $\mathrm{Ag}(\mathrm{Au})$ colloids. $\mathrm{Ag} / \mathrm{SiO}_{2}$ powders were tested after treating at $85-90^{\circ} \mathrm{C}, \mathrm{Au} / \mathrm{SiO}_{2}-$ after $500^{\circ} \mathrm{C}$. The probes were diluted in distilled water with the concentration of $0.0016 \%$ wt. Me and of $3.13 \%$ wt. HDS in suspension. Colloids were tested with the concentration of $0.0016 \%$ wt. Me.

$\mathrm{AgNO}_{3}$ solution was used in the control experiments in the equal concentration as Ag NPs. Binary stabilizer PVP/SDS and $\mathrm{NaBH}_{4}$ were studied in the control with the same amount as in the colloids. Initial HDS was tested also at the concentration $3.13 \% \mathrm{wt}$. in presence of the stabilizers and $\mathrm{NaBH}_{4}$.

The results of antimicrobial activity of Ag NPs in colloid and suspension against E. coli, S. aureus и C. albicans are presented in the Table 1.

Essential reduction values for bacteria E. coli $(5 \mathrm{lg})$ and fungi C. albicans (4 lg) in colloids were achieved after 1 hour of exposure of microbial cells with Ag NPs. Staphylococcus were more Ag NPs-resistant, particularly $4.35 \mathrm{lg}$ reduction was achieved only after 4 hour of exposure. Decrease in Ag concentration allowed to reveal the phenomenon mentioned. C. albicans bacteria were the most sensitive among of objects studied.

The control $\mathrm{AgNO}_{3}$ solution showed no antimicrobial action. The same result was also revealed for PVP/SDS and $\mathrm{NaBH}_{4}$ mixture. Thus experimental data presented indicated a high antimicrobial activity of silver colloids to all microorganisms.

Ag NPs embedding into $\mathrm{SiO}_{2}$ surface slightly decreased activity of $\mathrm{Ag} / \mathrm{SiO}_{2}$ suspension. The exposure time increased and changes in interaction character of $\mathrm{Ag}$ NPs with the microbial cells appeared.

The contact time for $4 \mathrm{lg}$ reduction reached for C. albicans remained the same as that in colloid $(1 \mathrm{~h})$. At the same time, $\mathrm{Ag} / \mathrm{SiO}_{2}$ resistance of E.coli rose. The reduction value was only $3.58 \mathrm{lg}$ after 4 hour contact time. On the contrary, S.aureus was more sensitive to $\mathrm{Ag} / \mathrm{SiO}_{2}$ then to $\mathrm{Ag}$ in colloid.

Nevertheless the antimicrobial activity of $\mathrm{Ag} \mathrm{NPs} / \mathrm{SiO}_{2}$ complex remained high in general.

Nanosized gold at the same concentration range showed no antibacterial action on the indicated microorganisms. As it was shown in [24], Au NPs suppressed bacteria 
Table 1. The antimicrobial activity of Ag NPs in colloids and suspensions.

\begin{tabular}{|c|c|c|c|c|}
\hline \multirow{2}{*}{ Samples and concentrations } & \multirow{2}{*}{ Exposure time, $\mathrm{h}$} & \multicolumn{3}{|c|}{ test-strains, $\lg \mathrm{R}^{*}$} \\
\hline & & E. coli & S. aureus & C. albicans \\
\hline \multirow{4}{*}{ Ag NPs $(0.0016 \% \mathrm{wt})$ colloid } & 1 & $>5.22$ & $<1.57$ & $>4.27$ \\
\hline & 2 & $>5.22$ & 2.07 & $>4.27$ \\
\hline & 4 & $>5.22$ & 4.35 & $>4.27$ \\
\hline & 24 & $>5.22$ & $>5.24$ & $>4.27$ \\
\hline initial microorganisms amount, $\operatorname{lgN}_{0}$ & & 7.37 & 7.39 & 6.42 \\
\hline \multirow{4}{*}{$\mathrm{Ag}$ NPs $(0.0016 \% \mathrm{wt}) / \mathrm{SiO}_{2}(3.13 \% \mathrm{wt})$} & 1 & $<1.39$ & 3.89 & $>4.54$ \\
\hline & 2 & 1.48 & 5.14 & $>4.54$ \\
\hline & 4 & 3.58 & $>5.17$ & $>4.54$ \\
\hline & 24 & $>5.06$ & $>5.17$ & $>4.54$ \\
\hline \multirow{4}{*}{$\mathrm{SiO}_{2}(3.13 \% \mathrm{wt})$ (control) } & 1 & $<1.39$ & $<1.5$ & $<0.87$ \\
\hline & 2 & $<1.39$ & $<1.5$ & $<0.87$ \\
\hline & 4 & $<1.39$ & $<1.5$ & $<0.87$ \\
\hline & 24 & $<1.39$ & $<1.5$ & $<0.87$ \\
\hline initial microorganisms amount, $\lg \mathrm{N}_{0}$ & & 7.21 & 7.32 & 6.69 \\
\hline
\end{tabular}

*According to European standards if the counts of CFU/ml sample are higher or lower than usual limits for counting microorganisms it must be reported the number as " $>$ value" or " $<$ value" for further calculation of number of survivors at the end of the contact-time $\mathrm{t}(\mathrm{Na})$ and reduction $(\mathrm{R})$ next.

growth for the first stage of their reproduction.

Experimental data presented in Table 1 indicated almost total growth inhibition of all studied microbes when the extremely low concentrations of nanosized Ag were used. It should be noted that antimicrobial rates were over 1-2 orders of magnitude than those given in literature.

\section{Conclusions}

Stable $\mathrm{Au}$ and $\mathrm{Ag}$ nanoparticles on $\mathrm{SiO}_{2}$ surface were obtained by adsorption of previously synthesized $\mathrm{Me}$ NPs colloids in presence of SDS and binary SDS/PVP stabilizing agents.

The fixation of the metal nanoclusters on silica surface was a result of: 1) interaction between the functional groups of stabilizer shell of NPs and OH-groups of silica; 2) location of Me NPs within secondary pores of HDS globules.

Composite systems obtained containing strongly bound and homogeneously distributed Ag NPs on silica surface served as potential wide-spectrum effective antimicrobial materials for water cleaning as well as for medical and pharmaceutical application.

\section{References}

[1] D. K. Tiwari, J. Behari, P. Sen, "Time and dosedependent antimicrobial potential of $\mathrm{Ag}$ nanoparticles synthesized by top-down approach," Current Science, Vol. 95, No. 5, pp. 647-655, September 2008.

[2] M. Kawashita, S. Toda, H-M. Kim, T. Kokubo, N. Masuda, "Preparation of antibacterial silver-doped silica glass microspheres," J.Biomedical Materials research, Part A, Vol. 66, No. 2, pp. 266-274, 2003.

[3] M. Hillenkamp, G. D. Domenicantonio, O. Eugster, C.
Félix, "Instability of $\mathrm{Ag}$ nanoparticles in $\mathrm{SiO}_{2}$ at ambient conditions," Nanotechnology, Vol. 18, pp. 015702, January 2007.

[4] E. D. Goddard, J. V. Gruber, "Principle of polymer science and technology in cosmetics and personal care," M. Dekker, New York, 1999.

[5] R. Patakfalvi, Z. Viranyi, I. Dekany, "Kinetics of silver nanoparticle growth in aqueous polymer solutions," Coll. Polym. Sci., Vol. 283, pp. 299-305, June 2004.

[6] L. Bois, F. Bessueille, E. Chassagneux, Y. Battie, N. Destouches, C. Hubert, A. Boukenter, S. Parola, "Silver nanoparticles growth in a mesoporous silica film templated with the F127 triblock copolymer," Coll. Surf. A: Physicochem. Eng. Aspects., Vol. 325, No. 1-2, pp. 86-92, 2008.

[7] M. P. Pileni, I. Lisiecki, L. Motte, C. Petit, I. Cizeron, N. Moumen, P. Lixon, "Nanoparticles synthesized in reverse micelles," Prog. Col. Polym. Sci., Vol. 93, No. 1, 1993.

[8] N. Toshima, T. Yonezava, K. Kushihashi, "Polymerprotected palladium - platinum bimetallic clusters: preparation, catalytic properties and structural considerations," J.Chem. Soc., Faraday Trans., Vol. 89, pp. 2537-2543, 1993.

[9] I. Mukha, A. Eremenko, N. Smirnova, G. Korchak, A. Mikhiyenkova, I. Chekman, "Formation, physical chemical and bactericide properties of stabilized silver nanostructures on the surface of disperse silica," (Russian), Chemistry, Physics and Technology of Surface, Kyiv: Naukova Dumka, Vol. 15, pp. 255-266, 2009.

[10] G. Krylova, A. Eremenko, N. Smirnova, S. Eustis, "Photogeneration of nanosized gold on the surface of mesoporous silica modified by benzophenone," Theor. and Experim. Chemistry. (Russian, Transl. English), Vol. 41, No. 6, pp. 365-370, November 2005.

[11] S. Eustis, G. Krylova, A. Eremenko, N. Smirnova, C. Tabor, W. Huang, M. El-Sayed, "Using silica films and 
powders modified with benzophenone to photoreduce silver nanoparticles," J. Photochem. Photobiol. A: Chem., Vol. 181, pp. 385-393, 2006.

[12] O. Akhavan, R. Azimirad, A. Z. Moshfegh, J. Phys. D: Appl. Phys., Vol. 41, No. 19, pp. 195305, 2008.

[13] G. V. Krylova, A. M. Eremenko, N. P. Smirnova, S Eustis, "Photochemical preparation of nanoparticles of $\mathrm{Ag}$ in aqueous-alcoholic solutions and on the surface of mesoporous silica," Theor. and Experim. Chemistry (Russian, Transl. English), Vol. 41, No. 2, pp. 100-104, March-April 2005.

[14] L. G. Grechko, A. M. Eremenko, G. V. Krylova, L. B. Lerman, N. P. Smirnova, N. G. Shkoda, "Optical properties of small silver particles within colloid solutions," (Ukr), Proceedings of Kyiv University, Series: Physics \& Mathematics, Vol. 4, pp. 450, 2004.

[15] J. P. Wilcoxon, R. L. Williamson, and R. Baughman, "Optical properties of gold colloids formed in inverse micelles,” J. Chem. Phys., Vol. 98, pp. 9933-9950, 1993.

[16] Y. N. Cheong Chan, R. R. Schrock, and R. E. Cohen, "Synthesis of silver and gold nanoclusters within microphase-separated diblock copolymers", Chem.Mater., Vol. 4, pp. 24-27, 1992.

[17] EN 13727, "Chemical disinfectants and antiseptics Quantitative suspension test for the evaluation of bactericidal activity in the medical area-Test method and requirements (phase 2, step 1)," Brussels, European
Committee for Standardization, September 2004.

[18] EN 13624, "Chemical disinfectants and antiseptics Quantitative suspension test for the evaluation of fungicidal or yeasticidal activity for instruments used in the medical area - Test method and requirements (phase 2, step 1)," Brussels, European Committee for Standardization, October 2002.

[19] Ch. Chen, L. Wang, G. Jiang, H. Yu, "Chemical preparation of special-shaped metal nanomaterials through encapsulation or inducement in soft solution," Research Adv. Mater., Vol. 11, pp. 1-18, 2006.

[20] Yu. S. Lipatov and L. M. Sergeeva, "Adsorption of Polymers," (Russian), Naukova Dumka, Kiev. 1972.

[21] S. R. Kline, E. W. Kaler, "Aggregation of colloidal silica by n-alkyl sulfates," Langmuir, Vol. 12, No. 10, pp. 2402-2407, March 1996.

[22] Y. Guo, A. Guadalupe, "Functional silica aerogel from metastable lamellar composite," Chem. Commun., pp. 315-316, January 1999.

[23] A. Lehninger, D. Nelson, M. Cox, "Principle of biochemistry," second ed., New York: Worth Publishers, 1993.

[24] G. Yashan, G. Krylova, A. Eremenko, N. Smirnova, V. Zhalko-Tytarenko, V. Marievskiy, I. Chekman, "Bactericide properties of gold and silver nanoparticles in solution and on high disperse silica surface," (Russian), Chemistry, Physics and Technology of Surface. Kyiv: Naukova Dumka, Vol. 14, pp. 524, 2008. 